\title{
Cardiac autonomic neuropathy in patients with diabetes mellitus: current perspectives
}

This article was published in the following Dove Press journal:

Diabetes, Metabolic Syndrome and Obesity:Targets and Therapy

6 October 2017

Number of times this article has been viewed

\author{
Victoria L Fisher' \\ Abd A Tahrani ${ }^{2-4}$ \\ 'School of Medicine, University \\ of Nottingham, Nottingham, \\ ${ }^{2}$ Institute of Metabolism and \\ Systems Research, University of \\ Birmingham, ${ }^{3}$ Department of Diabetes \\ and Endocrinology, Birmingham \\ Heartlands Hospital, ${ }^{4}$ Centre \\ for Endocrinology, Diabetes and \\ Metabolism, Birmingham Health \\ Partners, Birmingham, UK
}

\begin{abstract}
Cardiac autonomic neuropathy (CAN) is a common and often-underdiagnosed complication of diabetes mellitus (DM). CAN is associated with increased mortality, cardiovascular disease, chronic kidney disease, and morbidity in patients with DM, but despite these significant consequences CAN often remains undiagnosed for a prolonged period. This is commonly due to the disease being asymptomatic until the later stages, as well as a lack of easily available screening strategies. In this article, we review the latest developments in the epidemiology, pathogenesis, diagnosis, consequences, and treatments of CAN in patients with DM.

Keywords: cardiovascular, autonomic, neuropathy, orthostatic hypotension, postural hypotension, hyperglycemia, heart-rate variability, sympathetic, parasympathetic, deep breathing, Valsalva ratio, 30:15 ratio, Ewing tests, Ewing criteria
\end{abstract}

\section{Introduction}

Diabetes mellitus (DM) is a global health epidemic thought to be affecting 415 million people worldwide, with a further 318 million suffering with glucose intolerance and at increased risk of developing the disease. ${ }^{1}$ Cardiovascular disease (CVD) is the leading cause of mortality and morbidity in patients with DM, but diabetes-related microvascular complications also have a significant impact on morbidity and mortality. ${ }^{2-4}$

Cardiac autonomic neuropathy (CAN) is a common underdiagnosed complication of DM. ${ }^{5,6}$ The impact of CAN on patients with DM can be devastating, with CAN shown to be associated with increased mortality, CVD, chronic kidney disease (CKD), and morbidity of DM. ${ }^{6-8}$ The aim of this manuscript is to review the latest developments related to the epidemiology, pathogenesis, diagnosis, consequences, and treatment of CAN in patients with DM.

\section{Search strategies}

A review of literature was conducted using PubMed, Google Scholar, and Medline. Several terms were used in combination, including "cardiac", " autonomic", "neuropathy", “ dysfunction", "cardiomyopathy", "diabetes", "treatment”, "diagnosis", "definition", "pathophysiology", and "pathology". These results were limited to studies published in the English language between 2012 and 2017, but references from within those texts were also used. In addition, we also consulted our previous review of this topic that was published in $2014 .^{9}$

\section{CAN epidemiology}

Several studies examined the prevalence of CAN in patients with type 1 DM (T1DM) and type 2 DM (T2DM) (Table 1). These studies showed a large variation in CAN prevalence: ence: Abd A Tahrani Research, Medical School, University of Birmingham, Birmingham BI5 2TT, UK Email a.a.tahrani@bham.ac.uk 
$17 \%-66 \%$ in patients with T1DM and $31 \%-73 \%$ in patients with T2DM. This is thought to be due to discrepancies and variation in the criteria used to diagnose $\mathrm{CAN}$, study populations, and variation in CAN risk factors, as shown in Table $1 .{ }^{9}$

\section{CAN risk factors}

CAN has several risk factors that are common to other diabetes-related vascular complications, such as glycemic control, diabetes duration, and CVD risk factors, among others.

\section{Duration of diabetes}

Diabetes duration is a major risk factor for the development of CAN in patients with T1DM and T2DM. ${ }^{6,14-16}$ The incidence of CAN has been reported to be $6 \%$ and $2 \%$ annually in patients with T1DM and T2DM, respectively. ${ }^{9}$ The prevalence of CAN increased from $9 \%$ at the close of the DCCT study to $31 \% 1$ year later. ${ }^{24}$ Similarly, the prevalence of CAN increased from $19.8 \%$ in patients with prediabetes to $32.2 \%$ in patients newly diagnosed with T2DM, ${ }^{25}$ with higher prevalence reported in patients with T2DM and longer diabetes duration. ${ }^{14,26,27}$ The prevalence of CAN is often reported to be higher in T2DM compared to T1DM, despite the longer diabetes duration in patients with T1DM; this is likely a reflection of patients with T2DM often being older and more likely to have more CVD risk factors for CAN than patients with T1DM.

\section{Glycemic control}

Hyperglycemia plays an important role in the pathogenesis of diabetes-related microvascular complications, ${ }^{28}$ and hence it is not surprising that hyperglycemia has an unfavorable impact on the development and progression of CAN. DCCT showed a $50 \%$ decrease in CAN incidence over a 6.5 -year follow-up in its intensive-therapy cohort. ${ }^{15}$ The benefits of intensive glycemic control during DCCT persisted for at least 14 years after the end of the study, despite glycated hemoglobin $\left(\mathrm{HbA}_{1 \mathrm{c}}\right)$ differences between the intensive- and conventional-therapy arms disappearing after the end of randomization. ${ }^{29}$ Furthermore, participants in the DCCT intensive-therapy group who were free from $\mathrm{CAN}$ at the end of the study had a $31 \%$ reduction in risk of incident CAN when compared to those in the control arm (OR 0.69; 95\% CI 0.51-0.93). ${ }^{15}$ However, those individuals diagnosed with CAN at the end of DCCT showed a higher risk of suffering CVD events in follow-up, which was not independent of previous glycemic exposure or the effect of metabolic memory. ${ }^{24}$

\section{Cardiovascular risk factors}

CVD risk factors, including obesity, smoking, hypertension, and hyperlipidemia, have all been associated with
CAN development. ${ }^{14,30,31}$ In the EURODIAB prospective complications study, risk factors related to CAN development were investigated over a 7.3-year follow-up in patients with T1DM. The study showed that systolic blood pressure (SBP; OR 1.1/10 mmHg, 95\% CI 1-1.3), $\mathrm{HbA}_{1 \mathrm{c}}$ (OR 1.2 per percentage point, 95\% CI 1.1-1.4), and age (OR 1.3 per decade, 95\% CI 1.1-1.7) were associated with a higher risk of developing $\mathrm{CAN} .{ }^{31} \mathrm{~A}$ cross-sectional study of 2,230 participants with T2DM also showed that CAN patients had a higher prevalence of hypertension vs patients without CAN (57\% vs $49 \%, P<0.001){ }^{32}$

One study suggested that central obesity was associated with CAN, alongside age, postprandial glycemia, and diastolic blood pressure (DBP). ${ }^{25}$ Another study of 245 T1DM and $151 \mathrm{~T} 2 \mathrm{DM}$ patients showed that $\mathrm{CAN}$ was independently associated with obesity $(P=0.034)$ and that specifically in T2DM there was higher prevalence of CAN in obese patients $(P=0.033) .{ }^{33}$ It may thus be suggested that weight loss might a have favorable impact on $\mathrm{CAN} .^{34}$

\section{Microvascular complications}

Microvascular complications share common mechanisms, and several studies have shown that microvascular complications predict CAN development. For example, the EURODIAB study showed that the presence of retinopathy and albuminuria was associated with CAN. ${ }^{13} \mathrm{~A}$ large cohort study of 1,021 T2DM patients with CAN demonstrated that over a 7.5-year follow-up diabetic retinopathy (OR 1.513, 95\% CI 1.028-2.226; $P=0.036)$ and higher levels of microalbuminuria (OR 1.515, 95\% CI 1.031-2.228; $P=0.035$ ) predicted CAN progression. ${ }^{35}$ Similar results were found in a more recent study. ${ }^{36}$

\section{Sex}

The impact of sex on CAN epidemiology is controversial. The ACCORD trial, which included $>8,000$ patients with T2DM, showed higher CAN prevalence in women compared to men across all definitions of CAN used within the study. ${ }^{37}$ A more recent study, though not statistically significant, also showed women had higher prevalence of CAN than men $(65.2 \%$ vs $34.8 \%, P=0.059) .{ }^{38}$ However, other studies have shown no difference in CAN prevalence between men and women. . $^{13,32,39}$

\section{Ethnicity}

The impact of ethnicity on CAN prevalence has also been widely discussed in the literature, being cited as a possible risk factor for $\mathrm{CAN}$, as lower rates of peripheral neuropathy (PN) were detected in South Asians when compared to white 


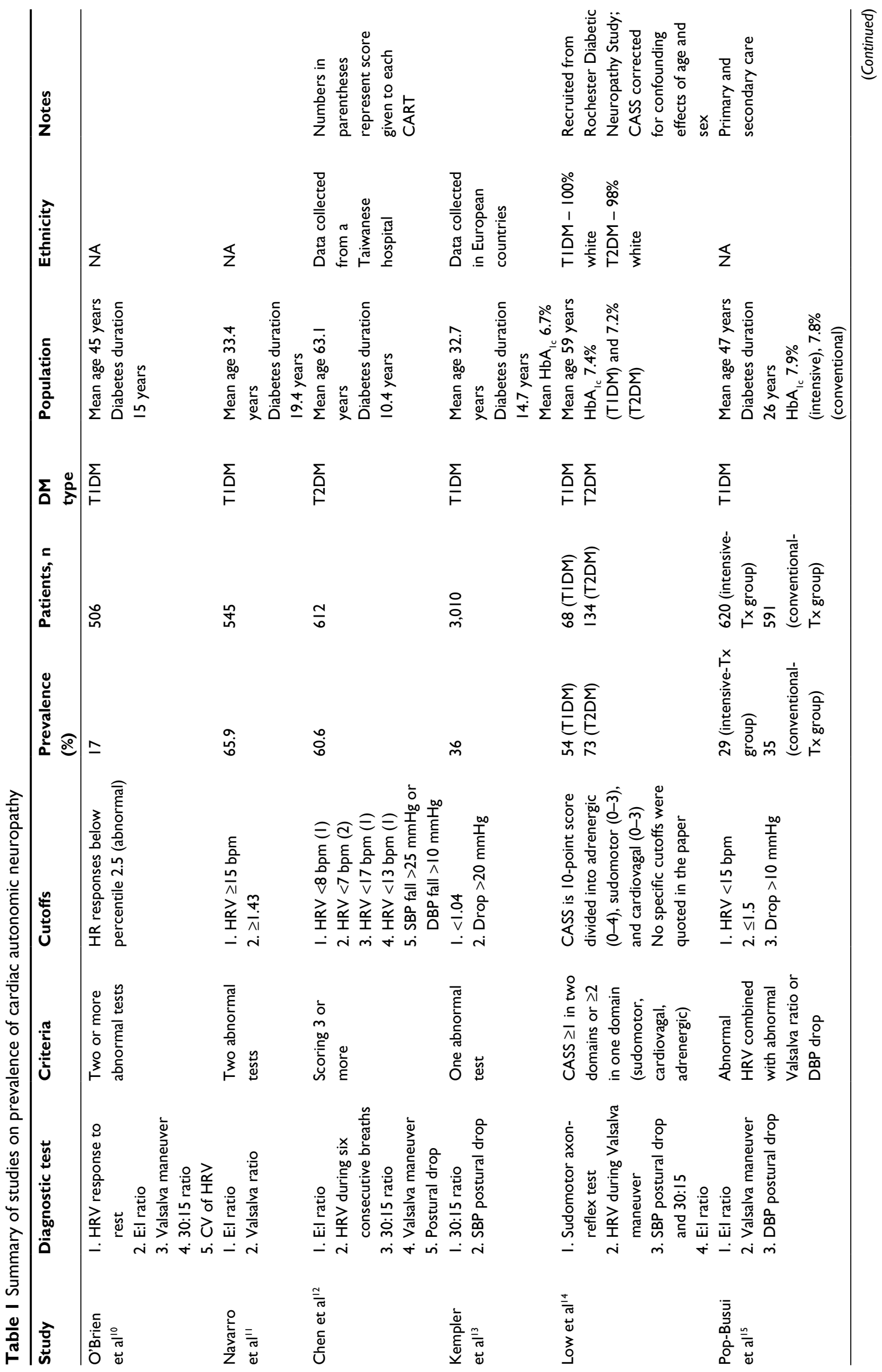




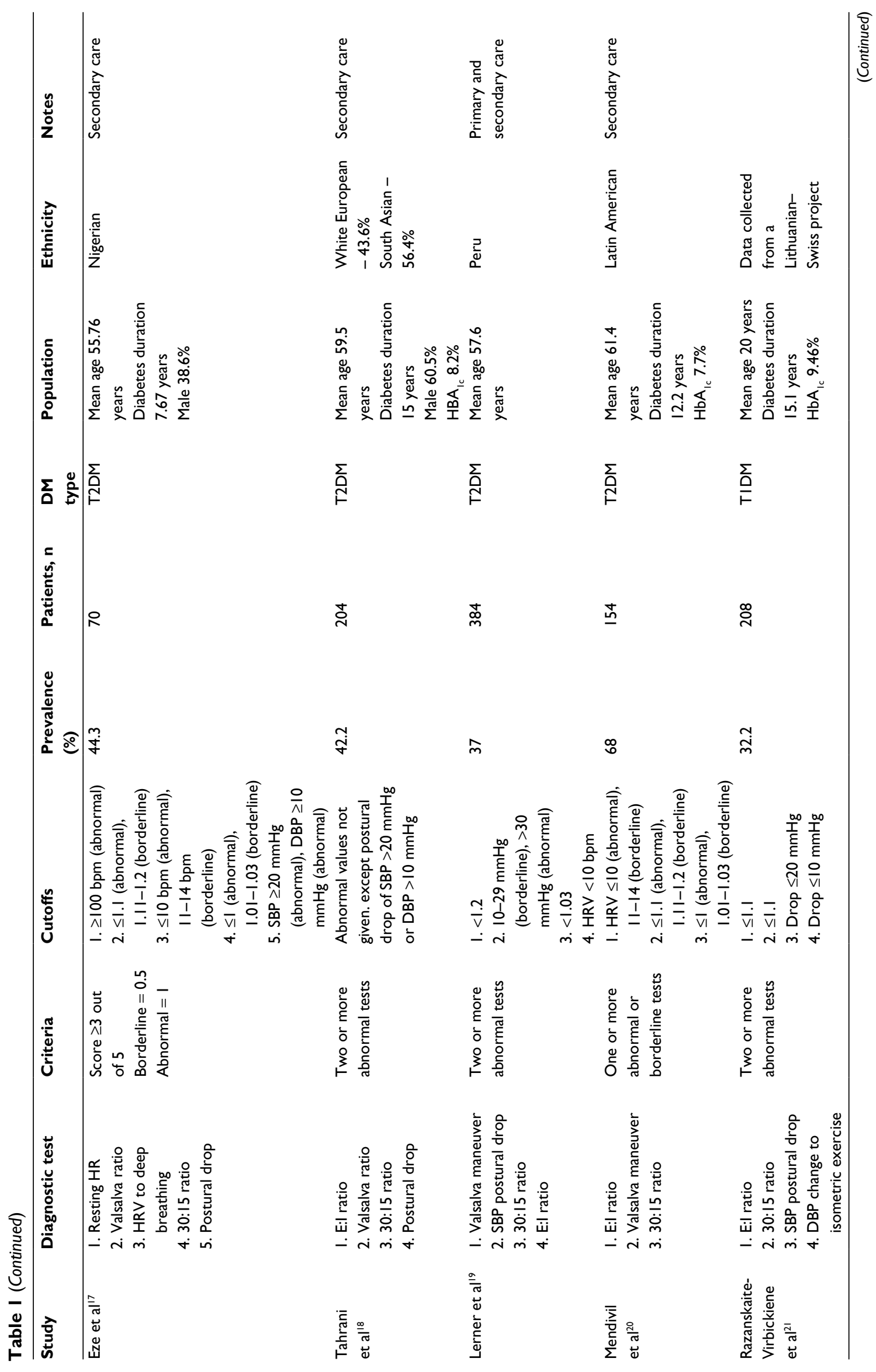




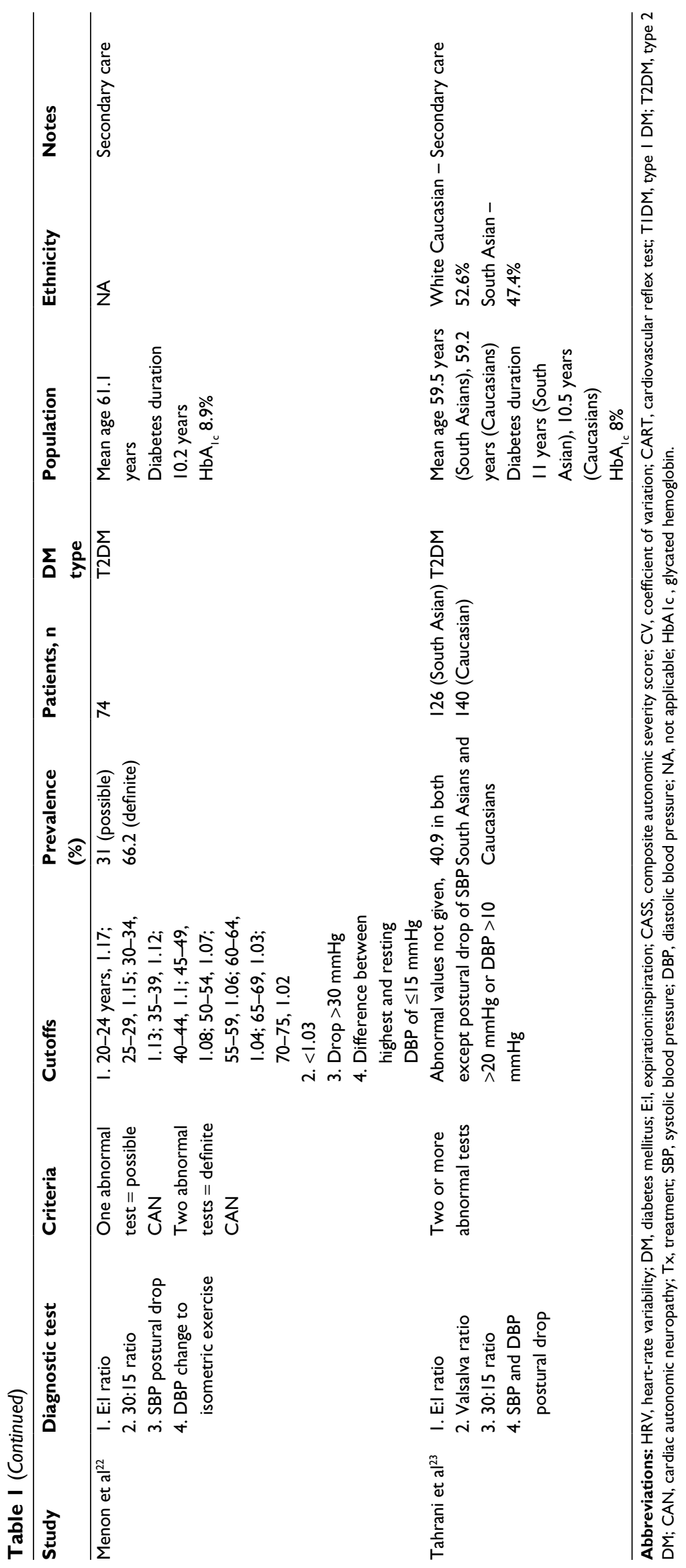


Europeans with DM. ${ }^{40}$ This was further supported in a recent study that showed white Caucasians were twice as likely to have diabetic PN (DPN) as South Asians, although this did become nonsignificant when adiposity and height were adjusted for. ${ }^{23}$ However, unlike PN, CAN prevalence has not been shown to be different between ethnicities, despite these ethnic differences in PN prevalence. ${ }^{23}$ This suggests that despite similarities in the pathogenesis of $\mathrm{PN}$ and autonomic neuropathy (AN) in patients with DM, there remain specific mechanisms that might affect one and not the other that need to be further explored.

\section{Pathogenesis of CAN}

CAN pathogenesis is complex, multifactorial, and still under much debate. Many of the proposed mechanisms are centered on models of neuronal injury based on somatic neuropathy, rather than AN. There are similarities between somatic neuropathy and $\mathrm{AN}$, but there are also differences, as was shown by the STENO-2 trial, ${ }^{41}$ in which the most recent follow-up showed that multifactorial intervention (including intensive therapy or CVD risk factors) can prevent the progression of AN, while the effects on somatic neuropathy were limited. ${ }^{41}$

\section{Hyperglycemia}

Hyperglycemia can activate multiple pathways involved in the pathogenesis of CAN. Of these pathways, the majority are related to the metabolic and/or oxidative state of neuronal cells. Although these alone can cause excessive damage, when combined they result in mitochondrial dysfunction and formation of reactive oxygen species (ROS). ${ }^{42}$ Oxidative stress can induce DNA damage, leading to activation of PARP and inhibition of GAPDH ${ }^{43}$ This in turn can activate multiple pathways, including the polyol pathway, the hexosamine pathway, as well as activation of PKC and increased production of advanced glycation end products, which in turn correlate with the severity of autonomic nerve abnormalities in patients with DM. ${ }^{42,44-47}$

Recent studies have supported the theory that hyperglycemia also impairs neuronal regeneration, and suggested that an increase in plasma superoxide generation may be able to predict decline in cardiac nerve function, and in particular may be the main determinant in early cardiac autonomic dysfunction. ${ }^{48-50}$ In relation to CAN, increased ROS is thought to depress autonomic ganglion synaptic transmission, contributing to increased risk of fatal cardiac arrhythmias, as well as to sudden death after myocardial infarction due to posttranslational protein modifications. ${ }^{51}$

\section{Autoimmunity}

CAN might occur as a result of autoimmune autonomic ganglionopathy. This is where autonomic failure occurs in the presence of antibodies to the nicotinic acetylcholine receptor of autonomic ganglia, leading to severe autonomic manifestations, eg, orthostatic intolerance, syncope, constipation, gastroparesis, urinary retention, dry mouth, dry eyes, anhidrosis, and cognitive impairment. ${ }^{52,53}$ However, the role of autoimmunity in patients with diabetes and CAN remains controversial. ${ }^{54-57}$ A recent small cross-sectional study did show that the presence of IgG antibodies was associated with AN (OR 9, 95\% CI 1.3-61.03). ${ }^{58}$ However, there remains no clear consensus on the role of autoimmunity in CAN progression, and most studies showing a positive association have been in patients with T1DM. Therefore, whether autoimmunity contributes to CAN in patients with T2DM is still not clear. ${ }^{57,59}$

\section{Genetics}

Several genes have been linked to the development and progression of diabetic polyneuropathy and CAN, among which are $T C F 7 L 2, A P O E$, and $A C E .{ }^{60}$ Ciccacci et al showed an association between miRI146a and miR27a single-nucleotide polymorphisms and CAN susceptibility. ${ }^{61}$ However, a twin study by Osztovits et al found that genetic factors did not have a substantial influence on CV autonomic function, and the authors went on to say that environmental factors played a bigger role. ${ }^{62}$

\section{Obstructive sleep apnea}

Obstructive sleep apnea (OSA) is known to be common in patients with DM and believed to be associated with DPN in patients with T2DM. ${ }^{63,64}$ While obesity is a major risk factor for OSA, Janovsky et al showed that OSA was common in lean patients with T1DM and that OSA can be associated with CAN. ${ }^{65}$ Unpublished data from our group showed that OSA was associated with weaker sympathetic and parasympathetic tone in patients with T2DM and that patients who were compliant with OSA treatment (continuous positive airway pressure) had improvements in several autonomic parameters over the follow-up period. ${ }^{66,67}$

The pathophysiology and relationship between OSA and CAN might differ between patients with T1DM and T2DM. The intermittent hypoxia that occurs with OSA could result in increased ROS and impaired microvascular function, leading to $\mathrm{CAN}^{64}$ On the other hand, the relationship may be bidirectional, with CAN causing changes in respiratory drive and upper-airway tone, increasing the risk of OSA. 


\section{Inflammation}

Inflammation plays an important role in the pathogenesis of diabetes and its related micro- and macrovascular complications. CAN has been associated with increased inflammatory markers such as CRP, IL6, and TNF $\alpha$, and adipose-tissue inflammation. ${ }^{47}$ However, the direction of the relationship between inflammation and CAN is not clear and could be bidirectional. ${ }^{47,68}$ Vinik et al suggested that the inflammatory response is controlled by a neural circuit in which the afferent arc consists of nerves that sense injury and transmits the information via the vagus nerve to the brain stem, which in turn activates the cholinergic anti-inflammatory pathways modulating the response. ${ }^{47}$ Increased activity in the vagus nerve to the spleen reduces the innate immune system's response to damage-associated molecular patterns and suppresses inflammation. ${ }^{47}$ Therefore, changes in vagal activity due to AN might have an impact on inflammatory responses.

\section{Clinical manifestations and consequences of CAN}

CAN only becomes symptomatic in the later stages of the disease as it advances (Figure 1) ${ }^{6,47}$ The denervation of both the autonomic and peripheral nervous systems occurs in an ascending length-dependent manner., ${ }^{9,67}$ Therefore, the vagus nerve is usually the first nerve to be affect in CAN, resulting in patients presenting with symptoms of sympathetic predominance. However, this is initially limited to baroreceptor abnormalities and changes in heart-rate variability (HRV), but as the disease progresses cardiac involvement becomes more evident and symptomatic.

\section{Resting tachycardia}

One of the earliest signs of CAN is asymptomatic abnormalities in heart rate (HR), which later progresses to resting tachycardia (90-130 bpm). ${ }^{47,71} \mathrm{~A}$ fixed and unresponsive HR to breathing is associated with complete cardiac denervation and severe CAN ${ }^{47,72}$ Therefore, resting HR can be used as a diagnostic and prognostic tool in patients with DM after excluding other causes of tachycardia. ${ }^{9}$ Furthermore, a study of 11,400 T2DM patients concluded that resting tachycardia is associated with an increased risk of death and CV complications (HR 1.15/10, 95\% CI 1.08-1.21; $P<0.001$ ). However, it was unclear whether this increased risk was a direct result of a higher resting HR or just a marker of other factors that may determine a poor outcome. ${ }^{73}$

\section{Reduced exercise tolerance}

Parasympathetic denervation and sympathetic predominance are known to impair exercise tolerance by reducing HR and blood pressure (BP) response to activity, as well as blunting the appropriate increases in cardiac output. ${ }^{47,71}$ Patients with CAN who are undertaking an exercise program should be warned that $\mathrm{HR}$ cannot be used as an indicator of exercise intensity. ${ }^{47,74}$

\section{Orthostatic hypotension}

Orthostatic hypotension is defined as a reduction in SBP $>20 \mathrm{mmHg}$ or DBP $>10 \mathrm{mmHg}$ following a postural change from supine to standing, and is deemed to be a late sign in CAN. ${ }^{71,74}$ In diabetes, it is thought to be the result of efferent sympathetic vasomotor denervation leading to a defective reflex arc, culminating in an inadequate HR response and peripheral vasodilation when a person stands. ${ }^{14,75}$ Symptoms can include faintness, dizziness, and light-headness, and in severe cases a syncopal episode. ${ }^{72}$ Several medications given to patients with diabetes can aggravate these symptoms, including diuretics, vasodilators, tricyclic antidepressants, and insulin. ${ }^{74,76}$

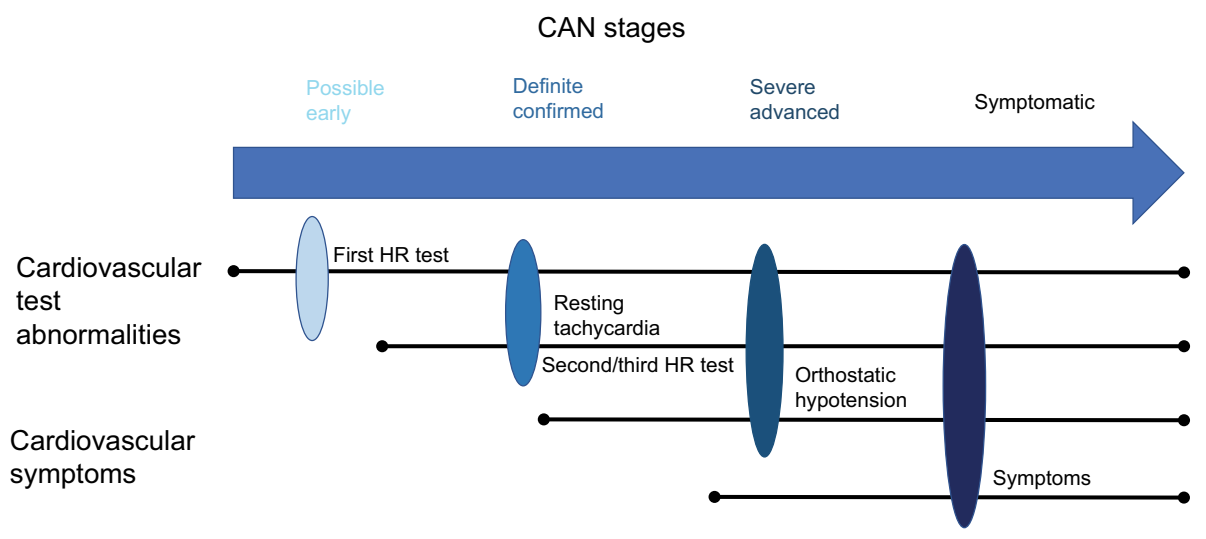

Figure I Stages of CAN.

Notes: CAN symptoms can include reduced exercise tolerance, silent ischemia, interoperative complications, and lower-limb complications. Adapted from Vinik Al, Erbas T, Casellini CM. Diabetic cardiac autonomic neuropathy, inflammation and cardiovascular disease. J Diabetes Investig. 20I3;4(I):4-I8. @ 20I3 Asian Association for the Study of Diabetes and Wiley Publishing Asia Pty Ltd. ${ }^{47}$

Abbreviations: CAN, cardiovascular autonomic neuropathy; HR, heart rate. 


\section{QT prolongation}

QT prolongation is associated with cardiac arrhythmias and sudden death. ${ }^{77}$ Its pathogenesis is multifactorial, but includes an imbalance in cardiac sympathetic innervation and left-ventricular hypertrophy, as is often seen in CAN. ${ }^{78}$

\section{Silent ischemia and CVD}

Silent coronary artery disease has been reported with varied prevalence (12\%-34\%) in patients with DM, and is dependent on age, diabetes duration, and the presence of other risk factors. $^{79-82}$ In the DIAD study, CAN (based on Valsalva ratio) was strongly associated with silent myocardial ischemia independently of traditional CVD risk factors ${ }^{47,81} \mathrm{CAN}$ was also associated with a prolonged subjective angina threshold, meaning that electrocardiography changes occur prior to the onset of angina pectoris, and thus CAN patients may be more susceptible to silent myocardial ischemia and/or infarction. ${ }^{83}$

A study by Valensi et al showed that CAN was a better predictor of a major cardiac event than silent ischemia $(P=0.04$ vs $P<0.05$ ), but that patients with $\mathrm{CAN}$ and associated silent ischemia had the highest risk. ${ }^{84} \mathrm{~A}$ meta-analysis of 12 crosssectional studies showed that CAN was associated with silent ischemia in patients with DM; the Mantel-Haenszel test estimated the prevalence risk ratio was 1.96 (95\% CI $1.53-2.51, P<0.001)$ for patients with CAN vs no CAN when CAN was defined using two or more measures. ${ }^{74}$ The pathophysiology linking these two conditions is still unclear, with several proposed mechanisms, including reduced pain threshold, changes to the myocardial autonomic pathways or ischemic processes, and a causative relationship with both conditions being the product of coronary artery disease present in diabetes. ${ }^{9}$

In the EURODIAB study, CAN was independently associated with CVD in patients with T1DM. ${ }^{31}$ Similarly, the DCCT and EDIC studies showed that CAN predicted long-term CVD events during follow-up. ${ }^{24} \mathrm{CAN}$ was also found to be a predictor of cerebrovascular disease over 5-10 years of follow-up in patients with T2DM. ${ }^{85-87}$

\section{Cardiomyopathy}

Diabetic cardiomyopathy results in systolic and diastolic dysfunction in the absence of structural and valvular cardiac disease, hypertension, or coronary vessel disease. ${ }^{88}$ The perceived mechanisms include left-ventricular hypertrophy, increased oxidative stress, altered substrate utilization, and mitochondrial dysfunction. ${ }^{89}$ The combination of sympathetic predominance and autonomic myocardial denervation leads to reduced coronary blood flow and thus diastolic and eventually systolic dysfunction. ${ }^{5,90}$

\section{Peri- and intraoperative complications}

Patients with CAN have a greater risk of anesthetic-related complications. Sufferers of CAN may have varied hemodynamic response to induction and tracheal intubation, leading to intraoperative hypotension, which is thought to be due to an inability to vasoconstrict correctly after the use of vasodilatory agents, such as anesthesia. ${ }^{91,92}$ Furthermore, patients with CAN have been shown to have a two- to threefold increase in perioperative morbidity and mortality as a result of severe intraoperative hypothermia. ${ }^{91-93}$ It is thus vital that all patients with a diabetes diagnosis are subject to a thorough preoperative assessment to minimize any of these complications perioperatively. ${ }^{91}$

\section{Lower-limb complications}

Sudomotor dysfunction, which can lead to foot ulceration, is due to both PN and AN. ${ }^{9}$ A study over 5 years of 595 patients with T2DM showed that the development of foot ulcers was independently associated with CAN after adjustment for possible confounding factors (normal vs definite CAN, HR 4.45, 95\% CI 1.29-15.33). ${ }^{94}$ In addition, a study by Chahal et al suggested that there may be an association between sudomotor dysfunction and peripheral artery disease, which can contribute to foot ulceration and lower-limb amputations. ${ }^{95}$ Autonomic dysfunction has been suggested to play an important role in the pathogenesis of Charcot neuroarthropathy in addition to periphery sensory and motor neuropathy. ${ }^{9}$

\section{Chronic kidney disease}

A recent study of 755 patients showed that CAN was an independent predictor for developing CKD in patients with T2DM after a 9.6-year follow-up (HR 2.62, 95\% CI 1.873.67; $P<0.001) .{ }^{96} \mathrm{CAN}$ was also an independent predictor of estimated glomerular filtration-rate decline in patients with T2DM in another study. ${ }^{18}$ Similarly, in patients with T1DM, CAN predicted the development of albuminuria and estimated glomerular filtration-rate decline over a 14-year period. ${ }^{97}$

\section{Anemia}

Anemia is positively associated with CAN in patients with T2DM, despite adjustment for sex, age, smoking habits, body-mass index, ALT, hyperlipidemia, hypertension, DM duration, $\mathrm{HbA}_{1 \mathrm{c}}$, retinopathy, and nephropathy. ${ }^{32}$ 


\section{Mortality}

Longitudinal studies have shown a 5-year mortality rate of $16 \%-50 \%$ in both T1DM and T2DM once CAN had been diagnosed, with most of these attributed to sudden cardiac death. ${ }^{9,72}$ This large range was due to differences in study population and methodologies used to diagnose CAN. These include changes in the perception of myocardial ischemia, altered hemodynamic response to stress on the CV system (eg, surgery, infection, or anesthesia), QT-interval dispersion leading to cardiac arrhythmias, variations in autonomic cardiac innervation balance and focal regions of sympathetic denervation, and reinnervation of the myocardium. ${ }^{8}$

A meta-analysis of 15 studies including studies with a baseline assessment of HRV using one or more tests and follow-up mortality data showed that the pooled estimated relative mortality risk was 3.45 ( $95 \%$ CI $2.66-4.47, P<0.001)$ when CAN was defined as the presence of two or more abnor- malities in cardiac autonomic function. ${ }^{9,98}$ The ACCORD trial also showed CAN to be an independent predictor of all-cause mortality (HR 2.14, 95\% CI 1.37-3.37) and CVD mortality (HR 2.62, 95\% CI 1.4-4.91) after a mean follow-up of 3.5 years,${ }^{37}$ while the EURODIAB IDDM complication study demonstrated that CAN had the strongest association with mortality when compared to other risk factors. ${ }^{99}$

\section{Diagnosis and screening of CAN Cardiac autonomic reflex tests}

Cardiac autonomic reflex tests (CARTs) were first described by Ewing et al in 1980 (Table 2). ${ }^{71,100}$ The CAN Subcommittee of the Toronto Consensus Panel defined CAN as the presence of at least two abnormal CARTs, presence of one abnormal CART as possible CAN, and presence of orthostatic hypotension with two or more abnormal CARTs as indicative of advanced CAN. ${ }^{6}$ CARTs are the gold standard in clinical

Table 2 Summary of Ewing tests

\begin{tabular}{|c|c|c|c|c|c|}
\hline CART & What does it assess? & $\begin{array}{l}\text { Which branch of the } \\
\text { autonomic nervous } \\
\text { system does it } \\
\text { measure? }\end{array}$ & $\begin{array}{l}\text { Interpretation and } \\
\text { definition }\end{array}$ & $\begin{array}{l}\text { Cutoffs (age- } \\
\text { dependent) }\end{array}$ & $\begin{array}{l}\text { Diagnostic } \\
\text { performance }^{101}\end{array}$ \\
\hline $\begin{array}{l}\text { HR response to } \\
\text { deep breathing } \\
\text { (E:I ratio) })^{103,111}\end{array}$ & $\begin{array}{l}\text { Assesses beat-to-beat } \\
\text { variation ( } R-R \text { variation) } \\
\text { during paced deep } \\
\text { breathing }\end{array}$ & $\begin{array}{l}\text { Tests for defects in } \\
\text { parasympathetic activity } \\
\text { by assessing ability of } \\
\text { vagal nerve to slow HR }\end{array}$ & $\begin{array}{l}\text { Gives an E:I ratio: longest } \\
\text { R-R during expiration } \\
\text { divided by shortest R-R } \\
\text { during inspiration }\end{array}$ & $\begin{array}{l}\text { I.22-I.I (15-65 } \\
\text { years) }\end{array}$ & $\begin{array}{l}S_{1}=19 \% \\
S_{2}=98 \% \\
P=0.115 \\
\text { OR }(95 \% C l)=2.34 \\
(I .19-4.77)\end{array}$ \\
\hline $\begin{array}{l}\text { HR response } \\
\text { to standing } \\
(30: 15 \text { ratio })^{103,111}\end{array}$ & $\begin{array}{l}\text { Assesses beat-to-beat } \\
\text { variation ( } R-R \text { variation) } \\
\text { following standing }\end{array}$ & $\begin{array}{l}\text { Tests for defects in } \\
\text { parasympathetic activity } \\
\text { by assessing ability of } \\
\text { vagal nerve to slow HR }\end{array}$ & $\begin{array}{l}\text { Gives the } 30: 15 \text { ratio: } \\
\text { R-R interval around } 30 \text { th } \\
\text { heartbeat divided by } R-R \\
\text { interval around the } 15 \text { th } \\
\text { heartbeat }\end{array}$ & $\begin{array}{l}1.17-1.06(15-65 \\
\text { years) }\end{array}$ & $\begin{array}{l}S_{1}=96 \% \\
S_{2}=65 \% \\
P<0.00 I \\
\text { OR }(95 \% \mathrm{Cl})=44.07 \\
(I 2.68-\mid 53.25)\end{array}$ \\
\hline $\begin{array}{l}\text { Valsalva maneuver } \\
\text { (Valsalva ratio) }^{104}\end{array}$ & $\begin{array}{l}\text { Evaluates HR response } \\
\text { during and after } \\
\text { provoked increase in } \\
\text { intrathoracic/abdominal } \\
\text { pressure }\end{array}$ & $\begin{array}{l}\text { Assesses both } \\
\text { parasympathetic and } \\
\text { sympathetic activity, but } \\
\text { mainly parasympathetic }\end{array}$ & $\begin{array}{l}\text { Gives Valsalva ratio: } \\
\text { longest R-R interval } \\
\text { in Phase IV divided by } \\
\text { shortest R-R interval } \\
\text { in Phase II and at very } \\
\text { beginning of Phase III }\end{array}$ & $\begin{array}{l}1.23-1.16(15-65 \\
\text { years })\end{array}$ & $\begin{array}{l}S_{1}=62 \% \\
S_{2}=92 \% \\
P=0.001 \\
\text { OR }(95 \% \mathrm{Cl})=18.56 \\
(5.55-62.1)\end{array}$ \\
\hline $\begin{array}{l}\text { BP response to } \\
\text { standing (reduction in } \\
\mathrm{SBP})^{103,106,110}\end{array}$ & $\begin{array}{l}\text { Assesses the } \\
\text { baroreceptor reflex }\end{array}$ & $\begin{array}{l}\text { Tests for defects in } \\
\text { sympathetic activity } \\
\text { by assessing ability to } \\
\text { provide suitable HR and } \\
\text { BP response to activity }\end{array}$ & $\begin{array}{l}\text { Test result presented as } \\
\text { difference in both SBP } \\
\text { and DBP between sitting } \\
\text { and standing }\end{array}$ & $\begin{array}{l}20 \text { drop in SBP or } \\
10 \text { drop in DBP }\end{array}$ & $\begin{array}{l}S_{1}=51 \% \\
S_{2}=71 \% \\
P=0.061 \\
O R(95 \% \mathrm{Cl})=2.5 \\
(I .28-4.88)\end{array}$ \\
\hline $\begin{array}{l}\text { BP response to } \\
\text { sustained muscle } \\
\text { contraction (rise in } \\
\text { DBP) }{ }^{103,105}\end{array}$ & $\begin{array}{l}\text { DBP increases caused } \\
\text { by sustained muscle } \\
\text { contraction with the } \\
\text { use of a handgrip } \\
\text { dynamometer }\end{array}$ & $\begin{array}{l}\text { Tests for defects in } \\
\text { sympathetic activity } \\
\text { by assessing ability to } \\
\text { provide suitable HR and } \\
\text { BP response to activity }\end{array}$ & $\begin{array}{l}\text { Test result presented } \\
\text { as difference between } \\
\text { highest DBP during } \\
\text { examination and average } \\
\text { DBP at rest }\end{array}$ & $\begin{array}{l}\text { Should normally be } \\
>15 \mathrm{mmHg}\end{array}$ & $\begin{array}{l}S_{1}=64 \% \\
S_{2}=75 \% \\
P=0.002 \\
O R(95 \% C l)=5.22 \\
(2.6-10.55)\end{array}$ \\
\hline
\end{tabular}

Notes: Phase I is a transient increase in BP and resulting bradycardia due to a mechanical rise in transthoracic pressure. Phase II is concomitant compensatory tachycardia due to reduced venous return and stroke volume leading to a decrease in BP. Phase III is a further transient reduction in BP and resulting tachycardia at the end of expiration due to pulmonary vasculature expansion. Phase IV is an abrupt rise in BP above baseline values with resulting bradycardia, thought to be the result of baroreceptor activation. Based on changes to hemodynamic parameters, various indices can be calculated, including the Valsalva ratio, which is derived from the longest R-R interval in Phase IV divided by the shortest R-R interval at the end of Phase II/beginning of Phase III. ${ }^{107}$ Normal values for cutoffs are age-dependent; some software manufacturers (such as Ansar) also provide their own normative values. $S_{1}$ is sensitivity and $S_{2}$ is specificity.

Abbreviations: HR, heart rate; CART, cardiac autonomic reflex test; E:I, expiration:inspiration; SBP, systolic blood pressure; DBP, diastolic blood pressure. 
autonomic testing, as they are all noninvasive, safe, and well standardized. ${ }^{21,100}$ While CARTs are measures of CAN, they are also measures of cardiac function, which can be affected in patients with CAN.

Pafili et al compared the results from each individual CART and their combination against Ewing's battery of tests. The study included 152 patients with a median diabetes duration of 12 years and mean age of $64.51 \pm 7.85$ years. It was concluded that the $30: 15$ ratio demonstrated the best diagnostic indicator for CAN, with 96\% sensitivity, 65\% specificity, $94 \%$ negative predictive value, and OR of 21.14 . It also suggested that if a 30:15 ratio indicated CAN, diagnostic accuracy could be increased if combined with the Valsalva ratio, a rise in DBP, and/or E:I ratio. ${ }^{101}$

In a study in a rural area of south India, 126 patients with T2DM were compared with 152 age- and sex-matched healthy controls. CAN prevalence was $53.2 \%$ in patients with T2DM, and HRV to deep breathing and DBP response to isometric exercise were the most sensitive tests for detecting parasympathetic and sympathetic AN when compared to all other Ewing CARTs. ${ }^{108}$ Abnormal values in Valsalva ratio, HRV to deep breathing, and immediate HR response to standing were used to diagnose parasympathetic dysfunction, and abnormal values in BP response to standing and $\mathrm{BP}$ response to isometric exercise were used to diagnose sympathetic dysfunction. ${ }^{108}$ Another study that evaluated patients with T1DM vs age- and sex-matched healthy controls demonstrated that HRV parameters and HR recovery were significantly reduced in T1DM patients when compared to their healthy counterparts and that HRV parameters also correlated with HR recovery. ${ }^{109}$

\section{Spectral analysis of heart-rate variability}

As previously discussed, CAN often remains subclinical before clinical manifestations are present. Subclinical CAN can be detected through a reduction in HRV. ${ }^{21}$ In healthy individuals, there is normal beat-to-beat variation during inspiration and expiration, which is driven by sympathetic and parasympathetic activity. ${ }^{9,110}$ Therefore, abnormal beatto-beat variations may be indicative of early changes to myocardial autonomic innervation. HRV may be assessed by time-domain analysis or frequency-domain analysis, with the former looking at statistical analysis of R-R intervals (SD of all normal R-R intervals and root-mean square of the difference of successive R-R intervals) and the latter at spectral analysis. ${ }^{21}$ Studies have shown that HRV abnormalities can be present at the time of diagnosis and that time- and frequency-domain analysis may permit more accurate evalu- ation of $\mathrm{CV}$ parasympathetic and sympathetic activity. ${ }^{21,76}$ Power spectral analysis of HRV can be carried out under resting conditions with demonstration of low-frequency (LF; 0.04-0.15 Hz) and high-frequency (HF; 0.15-0.4 Hz) components. The LF component of the power spectrum of HRV primarily reflects sympathetic activity, whereas the HF component (also termed the respiratory frequency [RF]) primarily reflects parasympathetic activity. LF:RF ratios are calculated, and provide a measure of sympathetic/parasympathetic activity (Figure 2 ). ${ }^{3}$

\section{Scintigraphy}

Scintigraphy allows the quantitative evaluation of sympathetic cardiac innervation through the use of single-photon-emission computed tomography \pm positron-emission tomography and sympathetic neurotransmitter analogues, such as ${ }^{123}$ I-metaiodobenylguanide and ${ }^{11} \mathrm{C}$-metahydroxyephedrine, respectively. ${ }^{9,76}$ However, these tests are specialized and expensive, and hence most of their use is limited to research studies, rather than routine clinical care.

\section{Baroreflex sensitivity}

An increase in BP is normally detected by baroreceptors, inducing a reflective increase in vagal activity and reduction in sympathetic activity. ${ }^{9}$ This results in a reduction in cardiac output, as well as peripheral vasodilation to control the increase in BP. ${ }^{9}$ The opposite occurs when there is a reduction in BP, and thus baroreflex sensitivity (BRS) can assess both sympathetic and parasympathetic activities. ${ }^{9}$

BRS can be examined using pharmacological methods (such as intravenous bolus injection of epinephrine) or nonpharmacological techniques (physical maneuvers, such as postural change). ${ }^{9}$ The former is considered the gold standard to date for evaluating BRS. Both techniques require a continuous measure of BP and a continuous and synchronized measure of HR (R-R interval). ${ }^{9}$ Furthermore, BRS can be estimated spontaneously through the observation of fluctuations of BP and R-R intervals. ${ }^{111}$

The use of BRS as a method of CAN diagnosis has also been looked at in comparison to healthy controls. Kamińska et al found that BRS was significantly lower in T1DM patients with CAN than those without CAN and that BRS did not differ significantly between those without CAN and the sex- and age-matched control group. ${ }^{112}$ This was further supported by a study showing that T1DM patients had decreased mean BRS in both $\mathrm{ms} / \mathrm{mmHg}$ and $\mathrm{mHz} /$ $\mathrm{mmHg}$ when compared to age-matched controls $(P=0.05$ and $P=0.17$, respectively). ${ }^{113}$ 


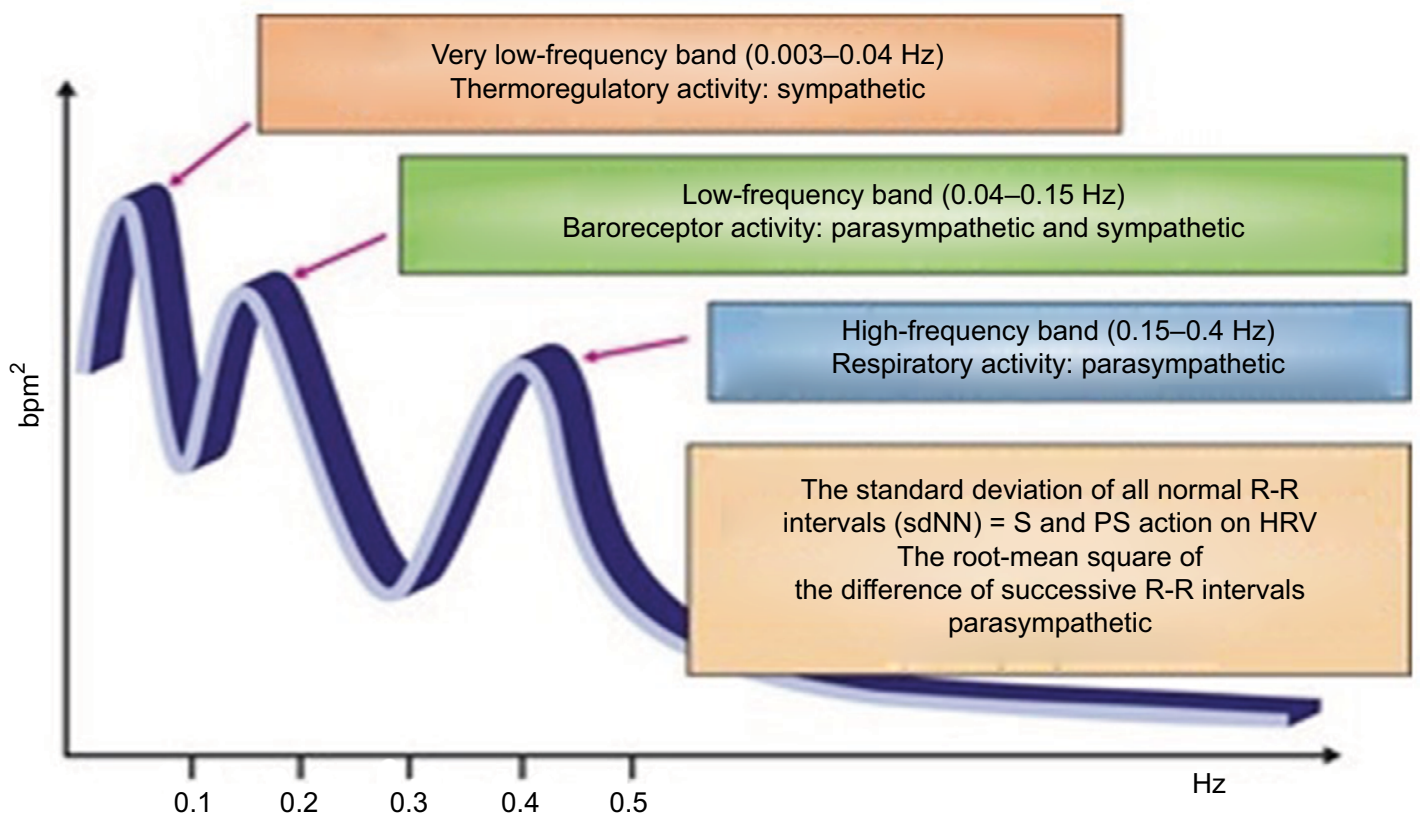

Figure 2 Spectral analysis of HRV.

Note: Reproduced from Vinik AI, Erbas T, Casellini CM. Diabetic cardiac autonomic neuropathy, inflammation and cardiovascular disease. J Diabetes Investig. 20I3;4(I):4-I8. (C) 2013 Asian Association for the Study of Diabetes and Wiley Publishing Asia Pty Ltd. ${ }^{47}$

Abbreviations: HRV, heart-rate variability; PS, parasympathetic; S, sympathetic ; sdNN, standard deviations of all normal beat-to-beat intervals.

\section{Corneal confocal microscopy}

Corneal confocal microscopy $(\mathrm{CCM})$ is an ophthalmic imaging technique that can accurately determine damage to corneal nerve fibers in patients with diabetes. These fibers have been shown to have a similar structure to type $A \delta$ and small autonomic $\mathrm{C}$ fibers, and thus CCM may be able to detect CAN. ${ }^{114}$ Tavakoli et al found that CCM may be used to diagnose subclinical and overt diabetic AN (DAN; based on the composite autonomic scoring scale). ${ }^{115}$ There were progressive and significant reductions in nerve-fiber density, nerve-branch density, and nerve-fiber length in patients with DAN vs healthy control and patients without DAN. Another study showed that CCM could represent a new and noninvasive tool in the diagnosis of CAN in T1DM, as corneal nerve-fiber density was lower in patients with CAN vs without CAN (based on HRV and postural hypotension). ${ }^{116}$ This is still an evolving area of research, but could present a new noninvasive method for CAN screening and diagnosis in the future.

\section{Screening}

The Toronto Consensus Panel recommended screening for CAN, as it can be used as a risk-stratification tool for diabetes-related complications and $\mathrm{CV}$ mortality and morbidity. ${ }^{6}$ The American Diabetes Association also recommended screening for CAN at the time of diagnosis for T2DM and within 5 years of diagnosis for T1DM, particularly if other complications are present. ${ }^{117} \mathrm{CAN}$ screening should also be considered in patients with DM who are undergoing elective surgery, as well as those patients who have suffered from cardiac events, including following myocardial infarction, as CAN predicted adverse outcomes., ${ }^{3,29}$

\section{Treatment of CAN}

Early determination of CAN is vital to the success of therapeutic input, as it has been suggested that $\mathrm{CV}$ denervation may be reversible if diagnosed soon after onset. ${ }^{118}$ The aim of CAN treatment is symptom control or slowing progression. Current methods use a combination of nonpharmacological and pharmacological approaches, including lifestyle modification, intensive glycemic control, and treating underlying risk factors, such as hyperlipidemia and hypertension.

Despite similarities in the pathogenesis of CAN and DPN, they are not the same disease. The STENO-2 trial showed improvements in CAN, but not DPN. ${ }^{41}$ In addition, CAN and DPN do not always coexist, despite similar pathogenesis, suggesting that these two conditions are not the same. It has also been shown that the ethnic differences seen in DPN prevalence between South Asians and white Caucasians are not seen in CAN. This could contribute to the differences observed between CAN and DPN responses to treatment. However, when considering treatment, it is important to consider the 
treatment modality and how responses were measured. For example, an improvement in the gold standard for DPN nerve-conduction studies - does not necessarily correlate with an improvement in CAN and vice versa, whereas if CCM, discussed earlier, were used as a measure of DPN, it may lead to a different result. Indeed, following islet-cell transplant, CCM shows improvements in corneal nerves. ${ }^{115,116}$

\section{Lifestyle modifications}

Increased physical activity has been demonstrated to improve HRV and lower resting HR. ${ }^{119}$ Even simple activity, such as dog walking, could improve parasympathetic activity. ${ }^{120}$ The Diabetes Prevention Program demonstrated that lifestyle modifications were superior to metformin or placebo in regard to improvement in autonomic dysfunction (assessed with HRV and QT indices). ${ }^{121}$ A review by Voulgari et al concluded that moderate endurance and aerobic exercise improved HRV and parasympathetic dominance in patients with T1DM or T2DM. ${ }^{122}$ Esposito et al suggested that improvement in autonomic function following physical activity may be related to improvements in tissue hypoxia. ${ }^{123}$

\section{Intensive glycemic control}

The DCCT trial showed that intensive glycemic control reduced $\mathrm{CAN}$ incidence by $50 \%$ in T1DM over a 6.5 -year follow-up when compared to conventional therapy (7\% vs 14\%, $P<0.004) .{ }^{15,29,124}$ These beneficial effects of intensive glycemic control in DCCT persisted during long-term followup in the EDIC study, ${ }^{15}$ and thus early intervention with intensive therapy in patients with T1DM may help reduce the progression and development of CAN. Additionally, the SEARCH CVD study looked at subclinical autonomic dysfunction in 354 young T1DM patients. Dysfunction was assessed with HRV testing and the presence of parasympathetic loss with sympathetic override, and $\mathrm{HbA}_{1 \mathrm{c}}>7.5 \%$ was independently associated with the presence of subclinical CAN when compared to a control group without DM. ${ }^{125}$

The effects of intensive glycemic control on CAN in patients with T2DM is still unclear. ${ }^{5}$ The Veterans Affairs Cooperative Study suggested no impact of intensive glycemic control on CAN. ${ }^{126}$ In another randomized controlled trial (RCT), intensive glycemic control in newly diagnosed T2DM in primary care did not have an impact on CAN prevalence at 6-year follow-up. ${ }^{39}$ Conversely, the STENO-2 trial demonstrated that intensive multifactorial treatment (including behavior modification and intensive therapy targeting hyperglycemia and CVD risk factors) lowered progression to AN (based on HRV during paced breathing and orthostatic hypotension $)$ in T2DM (OR 0.32, 95\% CI 0.12-0.78): ${ }^{127}$ these benefits were sustained at the 2 -year follow-up. ${ }^{41}$

\section{Pathogenesis-based pharmacotherapy}

As discussed in the pathogenesis of CAN, hyperglycemia results in the production of excessive ROS, resulting in endothelial dysfunction and neuronal disease. ${ }^{34}$ Therefore, several antioxidants have been suggested as treatment for CAN. Small studies using $\alpha$-lipoic acid and vitamin E suggested that these agents might have a favorable impact on CAN. ${ }^{6,34,128,129}$ However, a more recent RCT that used a triple-antioxidant regime (allopurinol, $\alpha$-lipoic acid, and nicotinamide) over the course of 2 years failed to prevent progression of CAN and had no effect on myocardial perfusion, as demonstrated with scintigraphic imaging modalities. ${ }^{130}$ The effects of $\alpha$-lipoic acid in the DEKAN RCT were only modest and only seen at 4 months. ${ }^{128} \mathrm{~A}$ small RCT in patients with T1DM also showed that C-peptide treatment might improve CAN over a 6-month period. ${ }^{131}$

Aldose reductase inhibitors, which block the polyol pathway, have been shown to improve autonomic function in three or more of the standardized CARTs, but were ineffective in advanced CAN. ${ }^{132}$ Another study found that aldose reductase inhibitors stabilized or partially reversed left-ventricular abnormalities in patients with CAN. ${ }^{133}$ ACE inhibitors, particularly quinapril, have also been shown to improve parasympathetic/sympathetic imbalance..$^{30,133,134} \mathrm{ACE}$ inhibitors may also be combined with $\alpha$-lipoic acid to increase HRV, as demonstrated by Ziegler et al. ${ }^{135}$ Cardioselective $\beta$-blockers can have a positive effect on autonomic dysfunction. ${ }^{136}$ Ebbehøj et al found that metoprolol improved autonomic function in patients with T1DM when used in combination with an ACE inhibitor. ${ }^{137}$ In the Beta-Blocker Heart Attack trial, propranolol was given to patients with DM following myocardial infarction, and was shown to improve parasympathetic tone and decrease morning sympathetic predominance. ${ }^{138}$

\section{Treatment of orthostatic hypotension}

Management of orthostatic hypotension in CAN is complex, and the condition is difficult to treat. ${ }^{5}$ Nonpharmacological interventions include increasing water consumption, avoiding sudden changes in body posture, reducing physical maneuvers that increase intra-abdominal and intrathoracic pressure, use of stockings of the lower extremities, and eating smaller and more frequent meals. ${ }^{5,80}$ Additionally, certain medications have been associated with orthostatic hypotension and should thus be stopped in patients who are symptomatic, including tricyclic antidepressants, diuret- 
ics, and $\alpha$-adrenoreceptor antagonists. ${ }^{5,9}$ If these methods are unsuccessful, then pharmacological methods should be considered on a risk-benefit basis: weighing up an increase in standing BP against prevention of supine hypotension. ${ }^{9,80}$

Midodrine is a peripheral selective $\alpha_{1}$-adrenergic agonist that causes peripheral vasoconstriction of arterioles and veins and is the only Food and Drug Administration-approved drug, hence its common use. ${ }^{9}$ Other pharmacological agents used in the treatment of orthostatic hypotension include fludrocortisone, which is a synthetic mineralocorticoid, octreotide, which inhibits the release of vasoactive peptides in the gastrointestinal tract, leading to an increase in splanchnic vasoconstriction and a rise in mean arterial BP, erythropoietin, which increases intravascular volume and blood viscosity, and pyridostigmine, which is a cholinesterase inhibitor. ${ }^{139}$

\section{Conclusion}

CAN is very common and often undiagnosed in patients with DM. Intensive multifactorial intervention targeting lifestyle, glycemic control, and CVD risk factors prevents the development and slows the progression of CAN Identifying patients with CAN is important, as CAN is associated with increased mortality, CVD, CKD, perioperative morbidity, and lower-limb complications. As such, these patients should receive appropriate follow up and preventive treatments to prevent or slow the progression of these complications. CAN should be diagnosed as per the Toronto Consensus Panel statement using standardized CARTs. Further research into the pathogenesis of CAN is important, in order to identify novel treatment targets and develop new therapies.

\section{Acknowledgment}

AAT is a clinician scientist supported by the National Institute for Health Research in the UK. The views expressed in this publication are those of the authors and not necessarily those of the National Health Service, the National Institute for Health Research, or the Department of Health.

\section{Disclosure}

The authors report no conflicts of interest in this work.

\section{References}

1. International Diabetes Federation. IDF Diabetes Atlas. 7th ed. Brussels: IDF; 2015.

2. National Diabetes Information Clearinghouse. DCCT and EDIC: the Diabetes Control and Complications Trial and follow-up study. 2008. Available from: https://www.niddk.nih.gov/about-niddk/researchareas/diabetes/dcct-edic-diabetes-control-complications-trial-followup-study/Documents/DCCT-EDIC_508.pdf. Accessed July 19, 2017.
3. [No authors listed]. Epidemiology of Diabetes Interventions and Complications (EDIC): design, implementation, and preliminary results of a long-term follow-up of the Diabetes Control and Complications Trial cohort. Diabetes Care. 1999;22(1):99-111.

4. Domingueti CP, Dusse LM, Carvalho MG, de Sousa LP, Gomes KB, Fernandes AP. Diabetes mellitus: the linkage between oxidative stress, inflammation, hypercoagulability and vascular complications. J Diabetes Complications. 2016;30(4):738-745.

5. Balcıoğlu AS, Müderrisoğlu H. Diabetes and cardiac autonomic neuropathy: clinical manifestations, cardiovascular consequences, diagnosis and treatment. World J Diabetes. 2015;6(1):80-91.

6. Spallone V, Ziegler D, Freeman R, et al. Cardiovascular autonomic neuropathy in diabetes: clinical impact, assessment, diagnosis, and management. Diabetes Metab Res Rev. 2011;27(7):639-653.

7. Stables CL, Glasser RL, Feldman EL. Diabetic cardiac autonomic neuropathy: insights from animal models. Auton Neurosci. 2013;177(2):74-80.

8. Freeman R. Diabetic autonomic neuropathy. Handb Clin Neurol. 2014;126:63-79.

9. Dimitropoulos G, Tahrani AA, Stevens MJ. Cardiac autonomic neuropathy in patients with diabetes mellitus. World J Diabetes. 2014;5(1):17-39.

10. O'Brien IA, Mcfadden JP, Corrall RJ. The influence of autonomic neuropathy on mortality in insulin-dependent diabetes. $Q \mathrm{~J} \mathrm{Med}$. 1991;79(290):495-502.

11. Navarro X, Kennedy W, Aeppli D, Sutherland D. Neuropathy and mortality in diabetes: influence of pancreas transplantation. Muscle Nerve. 1996;19(8):1009-1016.

12. Chen HS, Hwu CM, Kuo BI, et al. Abnormal cardiovascular reflex tests are predictors of mortality in type 2 diabetes mellitus. Diabet Med. 2001;18(4):268-273.

13. Kempler P, Tesfaye S, Chaturvedi N, et al. Autonomic neuropathy is associated with increased cardiovascular risk factors: the EURODIAB IDDM complications study. Diabet Med. 2002;19(11):900-909.

14. Low PA, Benrud-Larson LM, Sletten DM, et al. Autonomic symptoms and diabetic neuropathy: a population-based study. Diabetes Care. 2004;27(12):2942-2947.

15. Pop-Busui R, Low PA, Waberski BH, et al. Effects of prior intensive insulin therapy on cardiac autonomic nervous system function in type 1 diabetes mellitus: the Diabetes Control and Complications Trial/ Epidemiology of Diabetes Interventions and Complications study (DCCT/EDIC). Circulation. 2009;119(22):2886-2893.

16. Pop-Busui R. Cardiac autonomic neuropathy in diabetes: a clinical perspective. Diabetes Care. 2010;33(2):434-441.

17. Eze C, Onwuekwe I, Ogunniyi A. The frequency and pattern of cardiac autonomic neuropathy (CAN) in type $2 \mathrm{dm}$ patients in a diabetic clinic in Enugu south-east Nigeria. Niger J Med. 2013;22(1):24-31.

18. Tahrani AA, Dubb K, Raymond NT, et al. Cardiac autonomic neuropathy predicts renal function decline in patients with type 2 diabetes: a cohort study. Diabetologia. 2014;57(6):1249-1256.

19. Lerner A, Bernabé-Ortiz A, Ticse R, et al. Type 2 diabetes and cardiac autonomic neuropathy screening using dynamic pupillometry. Diabet Med. 2015;32(11):1470-1478.

20. Mendivil C, Kattah W, OrduzA, Tique C, Cárdenas J, Patiño J. Neuropad for the detection of cardiovascular autonomic neuropathy in patients with type 2 diabetes. J Diabetes Complications. 2016;30(1):93-98.

21. Razanskaite-Virbickiene D, Danyte E, Mockeviciene G, Dobrovolskiene R, Verkauskiene R, Zalinkevicius R. Can coefficient of variation of time-domain analysis be valuable for detecting cardiovascular autonomic neuropathy in young patients with type 1 diabetes: a case control study. BMC Cardiovasc Disord. 2017;17(1):34.

22. Menon AS, Dixit A, Garg MK, Girish R. Cardiac autonomic neuropathy in patients with type 2 diabetes mellitus at high risk for foot ulcers. Indian J Endocrinol Metab. 2017;21(2):282-285.

23. Tahrani AA, Altaf QA, Piya MK, Barnett AH. Peripheral and autonomic neuropathy in South Asians and white Caucasians with type 2 diabetes mellitus: possible explanations for epidemiological differences. J Diabetes Res. 2017;2017:1273789. 
24. Pop-Busui R, Braffett BH, Zinman B, et al. Cardiovascular autonomic neuropathy and cardiovascular outcomes in the Diabetes Control and Complications Trial/Epidemiology of Diabetes Interventions and Complications (DCCT/EDIC) study. Diabetes Care. 2017;40(1):94-100.

25. Dimova R, Tankova T, Guergueltcheva V, et al. Risk factors for autonomic and somatic nerve dysfunction in different stages of glucose tolerance. J Diabetes Complications. 2017;31(3):537-543.

26. Pfeifer MA, Weinberg CR, Cook DL, et al. Autonomic neural dysfunction in recently diagnosed diabetic subjects. Diabetes Care. 1984;7(5):447-453.

27. Ziegler D. Diabetic cardiovascular autonomic neuropathy: prognosis, diagnosis and treatment. Diabetes Metab Rev. 1994;10(4):339-383.

28. Giacco F, Brownlee M. Oxidative stress and diabetic complications. Circ Res. 2010;107(9):1058-1070.

29. [No authors listed]. The effect of intensive diabetes therapy on measures of autonomic nervous system function in the Diabetes Control and Complications Trial (DCCT). Diabetologia. 1998;41(4):416-423.

30. Boulton AJ, Vinik AI, Arezzo JC, et al. Diabetic neuropathies: a statement by the American Diabetes Association. Diabetes Care. 2005;28(4):956-962.

31. Witte DR, Tesfaye S, Chaturvedi N, et al. Risk factors for cardiac autonomic neuropathy in type 1 diabetes mellitus. Diabetologia. 2005;48(1):164-171.

32. Chung JO, Park SY, Cho DH, Chung DJ, Chung MY. Anemia, bilirubin, and cardiovascular autonomic neuropathy in patients with type 2 diabetes. Medicine (Baltimore). 2017;96(15):e6586.

33. Valensi P, Pariès J, Attali JR. Cardiac autonomic neuropathy in diabetic patients: influence of diabetes duration, obesity, and microangiopathic complications - the French multicenter study. Metabolism. 2003;52(7):815-820.

34. Maser RE, Lenhard MJ. Cardiovascular autonomic neuropathy due to diabetes mellitus: clinical manifestations, consequences, and treatment. J Clin Endocrinol Metab. 2005;90(10):5896-5903.

35. Ko SH, Park SA, Cho JH, et al. Progression of cardiovascular autonomic dysfunction in patients with type 2 diabetes: a 7-year follow-up study. Diabetes Care. 2008;31(9):1832-1836.

36. Huang CC, Lee JJ, Lin TK, et al. Diabetic retinopathy is strongly predictive of cardiovascular autonomic neuropathy in type 2 diabetes. J Diabetes Res. 2016;2016:6090749.

37. Pop-Busui R, Evans GW, Gerstein HC, et al. Effects of cardiac autonomic dysfunction on mortality risk in the Action to Control Cardiovascular Risk in Diabetes (ACCORD) trial. Diabetes Care. 2010;33(7):1578-1584.

38. Tannus LR, Drummond KR, Clemente EL, da Matta MF, Gomes MB. Predictors of cardiovascular autonomic neuropathy in patients with type 1 diabetes. Front Endocrinol (Lausanne). 2014;5:191.

39. Charles M, Fleischer J, Witte DR, et al. Impact of early detection and treatment of diabetes on the 6-year prevalence of cardiac autonomic neuropathy in people with screen-detected diabetes: ADDITION-Denmark, a cluster-randomised study. Diabetologia. 2013;56(1):101-108.

40. Abbott CA, Chaturvedi N, Malik RA, et al. Explanations for the lower rates of diabetic neuropathy in Indian Asians versus Europeans. Diabetes Care. 2010;33(6):1325-1330.

41. Gæde P, Oellgaard J, Carstensen B, et al. Years of life gained by multifactorial intervention in patients with type 2 diabetes mellitus and microalbuminuria: 21 years follow-up on the Steno-2 randomised trial. Diabetologia. 2016;59(11):2298-2307.

42. Edwards JL, Vincent AM, Cheng HT, Feldman EL. Diabetic neuropathy: mechanisms to management. Pharmacol Ther. 2008;120(1):1-34.

43. Verrotti A, Prezioso G, Scattoni R, Chiarelli F. Autonomic neuropathy in diabetes mellitus. Front Endocrinol (Lausanne). 2014;5:205.

44. Soriano FG, Virág L, Szabó C. Diabetic endothelial dysfunction: role of reactive oxygen and nitrogen species production and poly(ADP-ribose) polymerase activation. J Mol Med. 2001;79(8):437-448.

45. Hosseini A, Abdollahi M. Diabetic neuropathy and oxidative stress: therapeutic perspectives. Oxid Med Cell Longev. 2013;2013:168039.
46. Adeshara KA, Diwan AG, Tupe RS. Diabetes and complications: cellular signaling pathways, current understanding and targeted therapies. Curr Drug Targets. 2016;17(11):1309-1328.

47. Vinik AI, Erbas T, Casellini CM. Diabetic cardiac autonomic neuropathy, inflammation and cardiovascular disease. J Diabetes Investig. 2013;4(1):4-18.

48. Polydefkis M, Griffin JW, McArthur J. New insights into diabetic polyneuropathy. JAMA. 2003;290(10):1371-6.

49. Ziegler D, Buchholz S, Sohr C, Nourooz-Zadeh J, Roden M. Oxidative stress predicts progression of peripheral and cardiac autonomic nerve dysfunction over 6 years in diabetic patients. Acta Diabetol. 2015;52(1):65-72.

50. Jaiswal M, Fingerlin TE, Urbina EM, et al. Impact of glycemic control on heart rate variability in youth with type 1 diabetes: the SEARCH CVD study. Diabetes Technol Ther. 2013;15(12):977-983.

51. Shah MS, Brownlee M. Molecular and cellular mechanisms of cardiovascular disorders in diabetes. Circ Res. 2016;118(11):1808-1829.

52. Gibbons C, Centi J, Vernino S, Freeman R. Autoimmune autonomic ganglionopathy with reversible cognitive impairment. Arch Neurol. 2012;69(4):461-466.

53. Gibbons C, Freeman R. Antibody titers predict clinical features of autoimmune autonomic ganglionopathy. Auton Neurosci. 2009;146(1-2):8-12.

54. Skärstrand H, Dahlin LB, Lernmark A, Vaziri-Sani F. Neuropeptide Y autoantibodies in patients with long-term type 1 and type 2 diabetes and neuropathy. J Diabetes Complications. 2013;27(6):609-617.

55. Stroud CR, Heller SR, Ward JD, Hardisty CA, Weetman AP. Analysis of antibodies against components of the autonomic nervous system in diabetes mellitus. QJM. 1997;90(9):577-585.

56. Granberg V, Ejskjaer N, Peakman M, Sundkvist G. Autoantibodies to autonomic nerves associated with cardiac and peripheral autonomic neuropathy. Diabetes Care. 2005;28(8):1959-1964.

57. Ejskjaer N, Arif S, Dodds W, et al. Prevalence of autoantibodies to autonomic nervous tissue structures in type 1 diabetes mellitus. Diabet Med. 1999;16(7):544-549.

58. Berntorp K, Frid A, Alm R, Fredrikson GN, Sjöberg K, Ohlsson B. Antibodies against gonadotropin-releasing hormone $(\mathrm{GnRH})$ in patients with diabetes mellitus is associated with lower body weight and autonomic neuropathy. BMC Res Notes. 2013;6:329.

59. Zanone MM, Raviolo A, Coppo E, et al. Association of autoimmunity to autonomic nervous structures with nerve function in patients with type 1 diabetes: a 16-year prospective study. Diabetes Care. 2014;37(4): 1108-1115.

60. Politi C, Ciccacci C, D'Amato C, Novelli G, Borgiani P, Spallone V. Recent advances in exploring the genetic susceptibility to diabetic neuropathy. Diabetes Res Clin Pract. 2016;120:198-208.

61. Ciccacci C, Morganti R, Di Fusco D, et al. Common polymorphisms in MIR146a, MIR128a and MIR27a genes contribute to neuropathy susceptibility in type 2 diabetes. Acta Diabetol. 2014;51(4):663-671.

62. Osztovits J, Horváth T, Littvay L, et al. Effects of genetic vs. environmental factors on cardiovascular autonomic function: a twin study. Diabet Med. 2011;28(10):1241-8.

63. Tahrani AA. Obstructive sleep apnoea in diabetes: does it matter? Diab Vasc Dis Res. Epub 2017 Jun 1.

64. Tahrani AA, Ali A, Raymond NT, et al. Obstructive sleep apnea and diabetic neuropathy: a novel association in patients with type 2 diabetes. Am J Respir Crit Care Med. 2012;186(5):434-441.

65. Janovsky CC, Rolim LC, De Sá JR, et al. Cardiovascular autonomic neuropathy contributes to sleep apnea in young and lean type 1 diabetes mellitus patients. Front Endocrinol (Lausanne). 2014;5:119.

66. Stevens M, Ali A, Dubb K, Begum S, Piya M, Tahrani A. Obstructive sleep apnoea is associated with cardiac autonomic abnormalities in patients with type 2 diabetes. Diabet Med. 2014;31:37. Available from: https://insights.ovid.com/diabetic-medicine/diame/2014/03/001/ obstructive-sleep-apnoea-associated-cardiac/110/00003135. Accessed September 21, 2017. 
67. Altaf Q, Ali A, Tahrani A. The impact of obstructive sleep apnoea on cardiac autonomic neuropathy in patients with type 2 diabetes: a longitudinal study. 2017. Available from: http://www.neurodiab2017. com/Portals/0/Docs/abstract_book.pdf. Accessed August 31, 2017.

68. Theilade S, Lyngbaek S, Hansen TW, et al. Soluble urokinase plasminogen activator receptor levels are elevated and associated with complications in patients with type 1 diabetes. J Intern Med. 2015;277(3):362-371.

69. Chung T, Prasad K, Lloyd TE. Peripheral neuropathy: clinical and electrophysiological considerations. Neuroimaging Clin $\mathrm{N}$ Am. 2014;24(1):49-65.

70. Albers JW, Pop-Busui R. Diabetic neuropathy: mechanisms, emerging treatments, and subtypes. Curr Neurol Neurosci Rep. 2014;14(8):473.

71. Vinik AI, Freeman R, Erbas T. Diabetic autonomic neuropathy. Semin Neurol. 2003;23(4):365-372.

72. Pop-Busui R. What do we know and we do not know about cardiovascular autonomic neuropathy in diabetes. J Cardiovasc Transl Res. 2012;5(4):463-478.

73. Hillis G, Woodward M, Rodgers A, et al. Resting heart rate and the risk of death and cardiovascular complications in patients with type 2 diabetes mellitus. Diabetologia. 2012;55(5):1283-1290.

74. Vinik AI, Ziegler D. Diabetic cardiovascular autonomic neuropathy. Circulation. 2007;115(3):387-397.

75. [No authors listed]. Consensus statement on the definition of orthostatic hypotension, pure autonomic failure, and multiple system atrophy. Neurology. 1996;46(5):1470.

76. Kuehl M, Stevens MJ. Cardiovascular autonomic neuropathies as complications of diabetes mellitus. Nat Rev Endocrinol. 2012;8(7): 405-416.

77. Ninkovic VM, Ninkovic SM, Miloradovic V, et al. Prevalence and risk factors for prolonged QT interval and QT dispersion in patients with type 2 diabetes. Acta Diabetol. 2016;53(5):737-744.

78. Veglio M, Chinaglia A, Cavallo-Perin P. QT interval, cardiovascular risk factors and risk of death in diabetes. $J$ Endocrinol Invest 2004;27(2):175-181.

79. Sargin H, Ozisik M, Ozisik NC, et al. The prevalence of silent ischemia in Turkish patients with type 2 diabetes mellitus. Tohoku J Exp Med. 2005;205(4):351-355.

80. Deluca AJ, Kaplan S, Aronow WS, et al. Comparison of prevalence of unrecognized myocardial infarction and of silent myocardial ischemia detected by a treadmill exercise sestamibi stress test in patients with versus without diabetes mellitus. Am J Cardiol. 2006;98(8):1045-1046.

81. Wackers FJ, Young LH, Inzucchi SE, et al. Detection of silent myocardial ischemia in asymptomatic diabetic subjects: the DIAD study. Diabetes Care. 2004;27(8):1954-1961.

82. Deluca AJ, Saulle LN, Aronow WS, Ravipati G, Weiss MB. Prevalence of silent myocardial ischemia in persons with diabetes mellitus or impaired glucose tolerance and association of hemoglobin A1c with prevalence of silent myocardial ischemia. Am J Cardiol. 2005;95(12):1472-1474.

83. Ambepityia G, Kopelman PG, Ingram D, Swash M, Mills PG, Timmis AD. Exertional myocardial ischemia in diabetes: a quantitative analysis of anginal perceptual threshold and the influence of autonomic function. J Am Coll Cardiol. 1990;15(1):72-77.

84. Valensi P, Sachs RN, Harfouche B, et al. Predictive value of cardiac autonomic neuropathy in diabetic patients with or without silent myocardial ischemia. Diabetes Care. 2001;24(2):339-343.

85. Töyry JP, Niskanen LK, Länsimies EA, Partanen KP, Uusitupa MI. Autonomic neuropathy predicts the development of stroke in patients with non-insulin-dependent diabetes mellitus. Stroke. 1996;27(8):1316-1318.

86. Cohen JA, Estacio RO, Lundgren RA, Esler AL, Schrier RW. Diabetic autonomic neuropathy is associated with an increased incidence of strokes. Auton Neurosci. 2003;108(1-2):73-78.

87. Ko SH, Song KH, Park SA, et al. Cardiovascular autonomic dysfunction predicts acute ischaemic stroke in patients with type 2 diabetes mellitus: a 7-year follow-up study. Diabet Med. 2008;25(10):1171-1177.
88. Hayat SA, Patel B, Khattar RS, Malik RA. Diabetic cardiomyopathy: mechanisms, diagnosis and treatment. Clin Sci. 2004;107(6):539-557.

89. Boudina S, Abel ED. Diabetic cardiomyopathy, causes and effects. Rev Endocr Metab Disord. 2010;11(1):31-39.

90. Vinik AI, Erbas T. Diabetic autonomic neuropathy. Handb Clin Neurol. 2013;117:279-294.

91. Oakley I, Emond L. Diabetic cardiac autonomic neuropathy and anesthetic management: review of the literature. AANA J. 2011;79(6):473-479.

92. Burgos LG, Ebert TJ, Asiddao C, et al. Increased intraoperative cardiovascular morbidity in diabetics with autonomic neuropathy. Anesthesiology. 1989;70(4):591-597.

93. Latson TW, Ashmore TH, Reinhart DJ, Klein KW, Giesecke AH. Autonomic reflex dysfunction in patients presenting for elective surgery is associated with hypotension after anesthesia induction. Anesthesiology. 1994;80(2):326-337.

94. Yun JS, Cha SA, Lim TS, et al. Cardiovascular autonomic dysfunction predicts diabetic foot ulcers in patients with type 2 diabetes without diabetic polyneuropathy. Medicine (Baltimore). 2016;95(12):e3128.

95. Chahal S, Vohra K, Syngle A. Association of sudomotor function with peripheral artery disease in type 2 diabetes. Neurol Sci. 2017;38(1):151-156.

96. Yun JS, Ahn YB, Song KH, et al. The association between abnormal heart rate variability and new onset of chronic kidney disease in patients with type 2 diabetes: a ten-year follow-up study. Diabetes Res Clin Pract. 2015;108(1):31-37.

97. Forsén A, Kangro M, Sterner G, et al. A 14-year prospective study of autonomic nerve function in type 1 diabetic patients: association with nephropathy. Diabet Med. 2004;21(8):852-858.

98. Maser RE, Mitchell BD, Vinik AI, Freeman R. The association between cardiovascular autonomic neuropathy and mortality in individuals with diabetes: a meta-analysis. Diabetes Care. 2003;26(6):1895-1901.

99. Soedamah-Muthu SS, Chaturvedi N, Witte DR, et al. Relationship between risk factors and mortality in type 1 diabetic patients in Europe: the EURODIAB Prospective Complications Study (PCS). Diabetes Care. 2008;31(7):1360-1366.

100. Ewing DJ, Campbell IW, Clarke BF. Assessment of cardiovascular effects in diabetic autonomic neuropathy and prognostic implications. Ann Intern Med. 1980;92(2 Pt 2):308-311.

101. Pafili K, Trypsianis G, Papzoglou D, Maltezos E, Papanas N. Simplified diagnosis of cardiovascular autonomic neuropathy in type 2 diabetes using Ewing's battery. Rev Diabet Stud. 2015;12(1-2):213-219.

102. Ziegler D, Laux G, Dannehl K, et al. Assessment of cardiovascular autonomic function: age-related normal ranges and reproducibility of spectral analysis, vector analysis, and standard tests of heart rate variation and blood pressure responses. Diabet Med. 1992;9(2):166-175.

103. Pfeifer MA, Cook D, Brodsky J, et al. Quantitative evaluation of cardiac parasympathetic activity in normal and diabetic man. Diabetes. 1982;31(4 Pt 1):339-345.

104. Sandroni P, Benarroch EE, Low PA. Pharmacological dissection of components of the Valsalva maneuver in adrenergic failure. $\mathrm{J} \mathrm{Appl}$ Physiol (1985). 1991;71(4):1563-1567.

105. Ewing DJ, Campbell IW, Murray A, Neilson JM, Clarke BF. Immediate heart-rate response to standing: simple test for autonomic neuropathy in diabetes. Br Med J. 1978;1(6106):145-147.

106. Borowik E, Grabowicz W, Grycewicz T, Lubiński A. Clinical usefulness of baroreflex sensitivity test in the detection of cardiovascular autonomic neuropathy in patients with type 2 diabetes mellitus. Pol Merkur Lekarski. 2015;39(233):277-280.

107. Zygmunt A, Stanczyk J. Methods of evaluation of autonomic nervous system function. Arch Med Sci. 2010;6(1):11-18.

108. Shrivastava S, Sukla P, Shrivastava P, Rao N. Assessment of the cardiac autonomic neuropathy among the known diabetics and age-matched controls using noninvasive cardiovascular reflex tests in a south-Indian population: a case-control study. Avicenna J Med. 2016;6(3):81-85.

109. Turker Y, Aslantas Y, Aydin Y, et al. Heart rate variability and heart rate recovery in patients with type 1 diabetes mellitus. Acta Cardiol. 2013;68(2):145-150. 
110. Montano N, Ruscone TG, Porta A, Lombardi F, Pagani M, Malliani A. Power spectrum analysis of heart rate variability to assess the changes in sympathovagal balance during graded orthostatic tilt. Circulation. 1994;90(4):1826-1831.

111. La Rovere M, Maestri R, Pinna G. Baroreflex sensitivity assessment: latest advances and strategies. Eur Cardiol. 2011;7(2):89-92.

112. Kamińska A, Tafil-Klawe M, Smietanowski M, et al. Spontaneous baroreflex sensitivity in subjects with type 1 diabetes with and without cardiovascular autonomic neuropathy. Endokrynol Pol. 2008;59(5):398-402.

113. Svačinová J, Honzíková N, Krtička A, Tonhajzerová I, Javorka K, Javorka M. Diagnostic significance of a mild decrease of baroreflex sensitivity with respect to heart rate in type 1 diabetes mellitus. Physiol Res. 2013;62(6):605-613.

114. Messmer EM, Schmid-Tannwald C, Zapp D, Kampik A. In vivo confocal microscopy of corneal small fiber damage in diabetes mellitus. Graefes Arch Clin Exp Ophthalmol. 2010;248(9):1307-1312.

115. Tavakoli M, Begum P, McLaughlin J, Malik R. Corneal confocal microscopy for the diagnosis of diabetic autonomic neuropathy. Muscle Nerve. 2015;52(3):363-370.

116. Maddaloni E, Sabatino F, Del Toro R, et al. In vivo corneal confocal microscopy as a novel non-invasive tool to investigate cardiac autonomic neuropathy in type 1 diabetes. Diabet Med. 2014;32(2): 262-266.

117. Buse JB, Ginsberg HN, Bakris GL, et al. Primary prevention of cardiovascular diseases in people with diabetes mellitus: a scientific statement from the American Heart Association and the American Diabetes Association. Circulation. 2007;115(1):114-126.

118. Howorka K, Pumprla J, Haber P, Koller-Strametz J, Mondrzyk J, Schabmann A. Effects of physical training on heart rate variability in diabetic patients with various degrees of cardiovascular autonomic neuropathy. Cardiovasc Res. 1997;34(1):206-214.

119. Soares-Miranda L, Sandercock G, Vale S, et al. Metabolic syndrome, physical activity and cardiac autonomic function. Diabetes Metab Res Rev. 2012;28(4):363-369.

120. Motooka M, Koike H, Yokoyama T, Kennedy NL. Effect of dogwalking on autonomic nervous activity in senior citizens. Med J Aust. 2006;184(2):60-63.

121. Carnethon MR, Prineas RJ, Temprosa M, et al. The association among autonomic nervous system function, incident diabetes, and intervention arm in the Diabetes Prevention Program. Diabetes Care. 2006;29(4):914-919.

122. Voulgari C, Pagoni S, Vinik A, Poirier P. Exercise improves cardiac autonomic function in obesity and diabetes. Metab Clin Exp. 2013;62(5):609-621.

123. Esposito P, Mereu R, De Barbieri G, et al. Trained breathing-induced oxygenation acutely reverses cardiovascular autonomic dysfunction in patients with type 2 diabetes and renal disease. Acta Diabetol. 2016;53(2):217-226.

124. Ceriello A, Esposito K, Ihnat M, Thorpe J, Giugliano D. Long-term glycemic control influences the long-lasting effect of hyperglycemia on endothelial function in type 1 diabetes. J Clin Endocrinol Metab. 2009;94(8):2751-2756.

125. Jaiswal M, Urbina EM, Wadwa RP, et al. Reduced heart rate variability among youth with type 1 diabetes: the SEARCH CVD study. Diabetes Care. 2013;36(1):157-162.
126. Azad N, Emanuele NV, Abraira C, et al. The effects of intensive glycemic control on neuropathy in the VA cooperative study on type II diabetes mellitus (VA CSDM). J Diabetes Complications. 1999;13(5-6):307-313.

127. Gæde P, Vedel P, Parving HH, Pedersen O. Intensified multifactorial intervention in patients with type 2 diabetes mellitus and microalbuminuria: the Steno type 2 randomised study. Lancet. 1999;353(9153):617-622.

128. Ziegler D, Schatz H, Conrad F, Gries FA, Ulrich H, Reichel G. Effects of treatment with the antioxidant $\alpha$-lipoic acid on cardiac autonomic neuropathy in NIDDM patients: a 4-month randomized controlled multicenter trial (DEKAN study). Deutsche Kardiale Autonome Neuropathie. Diabetes Care. 1997;20(3):369-73.

129. Manzella D, Barbieri M, Ragno E, Paolisso G. Chronic administration of pharmacologic doses of vitamin E improves the cardiac autonomic nervous system in patients with type 2 diabetes. Am J Clin Nutr. 2001;73(6):1052-1057.

130. Pop-Busui R, Stevens MJ, Raffel DM, et al. Effects of triple antioxidant therapy on measures of cardiovascular autonomic neuropathy and on myocardial blood flow in type 1 diabetes: a randomised controlled trial. Diabetologia. 2013;56(8):1835-1844.

131. Johansson BL, Borg K, Fernqvist-Forbes E, Kernell A, Odergren T, Wahren J. Beneficial effects of C-peptide on incipient nephropathy and neuropathy in patients with type 1 diabetes mellitus. Diabet Med. 2000;17(3):181-189.

132. Hu X, Li S, Yang G, Liu H, Boden G, Li L. Efficacy and safety of aldose reductase inhibitor for the treatment of diabetic cardiovascular autonomic neuropathy: systematic review and meta-analysis. PLoS One. 2014;9(2):e87096.

133. Johnson BF, Nesto RW, Pfeifer MA, et al. Cardiac abnormalities in diabetic patients with neuropathy: effects of aldose reductase inhibitor administration. Diabetes Care. 2004;27(2):448-454.

134. Athyros VG, Didangelos TP, Karamitsos DT, Papageorgiou AA, Boudoulas H, Kontopoulos AG. Long-term effect of converting enzyme inhibition on circadian sympathetic and parasympathetic modulation in patients with diabetic autonomic neuropathy. Acta Cardiol. 1998;53(4):201-209.

135. Ziegler D, Low PA, Freeman R, Tritschler H, Vinik AI. Predictors of improvement and progression of diabetic polyneuropathy following treatment with $\alpha$-lipoic acid for 4 years in the NATHAN 1 trial. J Diabetes Complications. 2016;30(2):350-356.

136. Baruch L, Anand I, Cohen IS, Ziesche S, Judd D, Cohn JN. Augmented short- and long-term hemodynamic and hormonal effects of an angiotensin receptor blocker added to angiotensin converting enzyme inhibitor therapy in patients with heart failure. Circulation. 1999;99(20):2658-2664.

137. Ebbehøj E, Poulsen PL, Hansen KW, Knudsen ST, Mølgaard H, Mogensen CE. Effects on heart rate variability of metoprolol supplementary to ongoing ACE-inhibitor treatment in type I diabetic patients with abnormal albuminuria. Diabetologia. 2002;45(7):965-975.

138. Lampert R, Ickovics JR, Viscoli CJ, Horwitz RI, Lee FA. Effects of propranolol on recovery of heart rate variability following acute myocardial infarction and relation to outcome in the Beta-Blocker Heart Attack Trial. Am J Cardiol. 2003;91(2):137-142.

139. Shibao C, Lipsitz LA, Biaggioni I. ASH position paper: evaluation and treatment of orthostatic hypotension. J Clin Hypertens (Greenwich). 2013;15(3):147-153.

Diabetes, Metabolic Syndrome and Obesity: Targets and Therapy

\section{Publish your work in this journal}

Diabetes, Metabolic Syndrome and Obesity: Targets and Therapy is an international, peer-reviewed open-access journal committed to the rapid publication of the latest laboratory and clinical findings in the fields of diabetes, metabolic syndrome and obesity research. Original research, review, case reports, hypothesis formation, expert

\section{Dovepress}

opinion and commentaries are all considered for publication. The manuscript management system is completely online and includes a very quick and fair peer-review system, which is all easy to use. Visit http://www.dovepress.com/testimonials.php to read real quotes from published authors. 